\title{
Investigation of the presence of Legionella pneumophila in water samples from Erzurum and surrounding provinces in Turkey
}

\author{
Ahmet Yilmaz ${ }^{1, A-F \oplus}$, Figen Orhan ${ }^{2, A-B, D-F} \oplus$ \\ ${ }^{1}$ Erzurum Provincial Directorate of Health, Erzurum, Turkey \\ ${ }^{2}$ Department of Medical Laboratory Techniques, Vocational School of Health Services, Ataturk University, Erzurum, Turkey \\ A - Research concept and design, B - Collection and/or assembly of data, C - Data analysis and interpretation, \\ $D$ - Writing the article, E-Critical revision of the article, F- Final approval of article
}

Yilmaz A, Orhan F. Investigation of the presence of Legionella pneumophila in water samples from Erzurum and surrounding provinces in Turkey Ann Agric Environ Med. 2021; 28(2): 255-259. doi: 10.26444/aaem/135052

\begin{abstract}
Introduction and objective. Legionnaires' disease, which is a waterborne disease leading to pneumonia that can result in death, is one of the major health issues today. The study aims to carry out a three-year retrospective review of routine Legionella follow-up analyses in various samples taken mostly from hospitals in the province of Erzurum and nearby provinces, and to discover a the frequency of isolation of the agent and serogroups from each kind of media.

Materials and method. The study included a total of 2,025 water samples taken from hospitals, hotels, Turkish baths and shopping malls in Erzurum,and 13 nearby cities between 2016 and 2018. Samples were filtered by $0.45 \mu$ m-diameter membrane filter paper in the Public Health Laboratory of Erzurum and examined for L. pneumophila using culture method, according to the criteria set out in ISO 11731-2.

Results. The presence of L. pneumophila was found in 65 of the 2,025 water samples taken in hospitals, and in none of 40 samples taken in hotels, Turkish baths and shopping malls. L. pneumophila serogroup 2-14 was detected in 46 (70.8\%) of 65 samples found positive, whereas L. pneumophila serogroup 1 was detected in 18 (27.7\%). Furthermore, both the $L$. pneumophila serogroup 2-14 and L. pneumophila serogroup 1 were detected simultaneously in one example (1.5\%). The first three samples indicate that the highest positivity rates were in hot water taps (11.6\%), hot water tanks $(6.1 \%)$ and shower heads (4.8\%).

Conclusions. The Prevalence rat of $L$. pneumophila was found to be quite low compared to other studies conducted in the western regions of Turkey. Legionella positivity was found to be higher in the hot water systems of hospitals and related points, compared to the other sample points.
\end{abstract}

\section{Key words}

Legionella pneumophila, hospital, hotel, water samples

\section{INTRODUCTION}

Legionnaires' disease was defined for the first time as a result of analyses performed after an outbreak of acute respiratory tract infection in 182 people who attended a meeting of the Pennsylvania American Legion held in Philadelphia in 1976, and caused the death of 29 of the participants. The source of the transmission of the disease were not exactly determined [1]. In the USA, the Center for Disease Control (CDC) revealed that the agent in this outbreak wasa gram-negative bacterium and named the agent Legionella pneumophila since it causes a pneumonia-like picture [2]. Currently, there are over 60 species of Legionella reported; however, the main cause of Legionnaires' disease worldwide is L. pneumophila [3, 4]. Legionella is transmitted to humans by aspiration of contaminated water and inhalation of contaminated aerosols and/or air conditioning gases [5-7]. Common factors contributing to Legionella persistence in water systems include biofilm formation, growth in amoebae, growth in nutrient-poor environments, and disinfectant resistance or tolerance $[8,9]$. Two major hotel-related cases

Address for correspondence: Ahmet YILMAZ, Erzurum Provincial Directorate of Health, Erzurum, Turkey

E-mail: aymet25@hotmail.com

Received: 08.12.2020; accepted: 26.03.2021; first published: 19.04.2021 of Legionnaires' disease have been reported in Turkey, the first of which involved 17 cases in a hotel in Kusadasi in 1994, and the other involved 16 cases in a hotel in Istanbul in 1997 [10].

\section{OBJECTIVES}

Species of Legionella survive for a long time in chlorinated city waters, tank waters and on wet surface, and can be transmitted to humans through such media. Therefore, the aim of this study was to carry out a three-year retrospective review of routine Legionella follow-up analyses in various samples taken from hospitals, hotels, Turkish baths and shopping malls in the province of Erzurum and surrounding provinces, and to determine the frequency of isolation of the agent, and serogroups from each kind of environments.

\section{MATERIALS AND METHOD}

The study included a total of 2,025 water samples taken from hospitals, hotels, Turkish baths and shopping malls in Erzurum and nearby provinces (Ağrı, Ardahan, Artvin, Bayburt, Bingöl, Erzincan, Giresun, Gümüşhane, Iğdır, Kars, 
Muş, Tunceli and Van) between 2016-2018. Analyses were carried out in the Public Health Laboratory of Erzurum, which is also the reference laboratory in the region, by the method described in the relevant circular issued by the Ministry of Health. All samples were examined for L. pneumophila using the culture method according to the criteria set out in ISO 11731-2.

The water samples were inoculated both directly and after concentration. Using a sterile $0.45 \mu \mathrm{m}$ diameter membrane filter paper, $50 \mathrm{ml}$ water samples were filtered. $5 \mathrm{ml}$ of sterile water were added to the filter paper which had sediment on it, and vortexed for 30 seconds. $2 \mathrm{ml}$ of this water were taken and $2 \mathrm{ml}$ of acid buffer added. For culturing, $100 \mu \mathrm{l}$ water was added after 3 minutes of waiting time to both the BCYE (buffered charcoal yeast extract) and the DGVP (dyeglycine-vancomycin-polymyxin B) agar medium. Inoculated plates were incubated at $36 \pm 2{ }^{\circ} \mathrm{C}$ in an environment of $90 \%$ humidity for 10 days. The plates were checked daily for growth after the $3^{\text {rd }}$ day of incubation. Plates with no visible colonies were incubated for the end of the period. Gram staining was performed with suspected Legionella cp colonies where the growth was observed within 3-5 days. For the bacillus-shaped bacteria that displayed weak gram-negative staining, 5\% sheep blood agar and BCYE agar media was passaged. The passaged samples were incubated at $37^{\circ} \mathrm{C}$ for 24-48 hours. Isolates that developed on the BCYE agar, but did not develop on the $5 \%$ sheep blood agar, were serologically confirmed by the latex agglutination test (Oxoid), and identified as belonging to the L. pneumophila serogroup 1, L. pneumophila serogroup 2-14, and Legionella species other than pneumophila. ATCC 43111 reference strain was used as a positive control.

Statistical analysis. SPSS 22.0 (SPSS Inc, Chicago, IL, USA) statistical package programme was used for evaluation of all data obtained and statistical analysis of the results. Chisquare test was used to evaluate the isolation and positivity of $L$. pneumophila, and the limit of significance was set at $p<0.05$. The approval of the Ethics Committee was not needed for the study, only an institutional permit was obtained from the Erzurum Health Directorate on 8 April 2019.

\section{RESULTS}

The number of samples taken in different months is shown in Table 1. Positive test results of L. pneumophila were found especially at the highest rate in April, May, and June. In November, no positivity was detected in any of the samples studied (Fig. 1). L. pneumophila positivity was detected in $65(3.2 \%)$ of the 2,025 samples of water samples taken from hospitals (94.8\%), hotels (1.6\%), Turkish baths (0.2\%) and shopping malls $(0.2 \%)$. L. pneumophila serogroup 2-14 was detected in 46 (70.8\%) of 65 samples found positive (Tab. 2, Tab. 3).

Samples were taken from different points, mostly sink taps $(41.8 \%)$, shower heads $(26.9 \%)$, cold water tanks (14.7\%), and hot water tanks (10.5\%) (Tab. 3). Positivity for L. pneumophila was found in 65 (3.2\%) of the 2,025 water samples. In serological typing performed with latex agglutination test from 65 samples, 46 (70.8\%) were identified as L. pneumophila serogroup 2-14, and 18 (27.7\%) as L. pneumophila serogroup-1. Also, in sample (1.5\%), both L. pneumophila serogroup 2-14 and L. pneumophila serogroup 1 were detected simultaneously.

Only positive results were obtained in samples taken from the hospitals. In 23 of 89 hospitals, L. pneumophila positivity was detected. No L. pneumophila spp was detected in any samples taken from hotels, public baths, and shopping malls. The highest positivity rates were found in the hot water taps (11.6\%), hot water tanks (6.1\%), and shower heads (4.8\%). No positivity was detected in any of the samples taken from artesian water tanks or cooling towers (Tab. 3). The difference between the groups was statistically significant $\mathrm{p}<0.05$.

Table 1. Distribution of sample numbers by month

\begin{tabular}{lcc}
\hline Month & Number of samples & Percent \\
\hline January & 66 & 3.3 \\
\hline February & 87 & 4.3 \\
\hline March & 104 & 5.1 \\
\hline April & 263 & 13.0 \\
\hline May & 374 & 18.5 \\
\hline June & 185 & 9.1 \\
\hline July & 104 & 5.1 \\
\hline August & 176 & 8.6 \\
\hline September & 147 & 7.2 \\
\hline October & 275 & 13.6 \\
\hline November & 176 & 8.7 \\
\hline December & 68 & 3.4 \\
\hline
\end{tabular}

Table 2. Prevalence of $L$. pneumophila in examined facilities

\begin{tabular}{lccc}
\hline Facility & $\begin{array}{c}\text { No. of facilities } \\
\text { examined }\end{array}$ & $\begin{array}{c}\text { No. of facilities } \\
\text { where positive water } \\
\text { samples were found }\end{array}$ & $\begin{array}{c}\text { No. of total samples } \\
\text { examined positive/total } \\
\text { (percent) }\end{array}$ \\
\hline Hospital & 89 & 26 & $65 / 1989(3.3 \%)$ \\
\hline Hotel & 3 & 0 & $0 / 32(0)$ \\
\hline Turkish Bath & 1 & 0 & $0 / 4(0)$ \\
\hline Shopping Mall & 1 & 0 & $0 / 4(0)$ \\
\hline Total & $\mathbf{9 4}$ & $\mathbf{2 6}$ & $\mathbf{6 5 / 2 0 2 5 ( 3 . 2 \% )}$ \\
\hline
\end{tabular}

Table 3. Prevalence of $L$. pneumophila at specific sampling points in hospitals

\begin{tabular}{lccc}
\hline Sampling point & $\begin{array}{c}\text { No. of } \\
\text { sampling } \\
\text { points } \\
\text { examined }\end{array}$ & $\begin{array}{c}\text { No. of sampling } \\
\text { points where } \\
\text { positive water } \\
\text { samples were found }\end{array}$ & $\begin{array}{c}\text { No. of water } \\
\text { samples examined } \\
\text { positive/total } \\
\text { (percent) }\end{array}$ \\
\hline Lavatory faucets & 848 & 16 & $16 / 848(1.9 \%)$ \\
\hline Shower heads & 546 & 26 & $26 / 546(4.8 \%)$ \\
\hline Cold water tank & 299 & 4 & $4 / 299(1.3 \%)$ \\
\hline Hot water tank & 213 & 13 & $13 / 213(6.1 \%)$ \\
\hline Mains water inlet & 51 & 1 & $1 / 51(2.0 \%)$ \\
\hline Hot water tap & 43 & 5 & $5 / 43(11.6 \%)$ \\
\hline Artesian water tank & 14 & 0 & $0 / 14(0 \%)$ \\
\hline Cooling tower & 11 & 0 & $0 / 11(0 \%)$ \\
\hline Total & $\mathbf{2 0 2 5}$ & $\mathbf{6 5}$ & $\mathbf{6 5 / 2 0 2 5 ( 3 . 2 \% )}$ \\
\hline
\end{tabular}

Our study was carried out on water samples taken from 14 provinces in eastern Turkey (Fig. 2). When considering the distribution of positive L. pneumophila test results by 


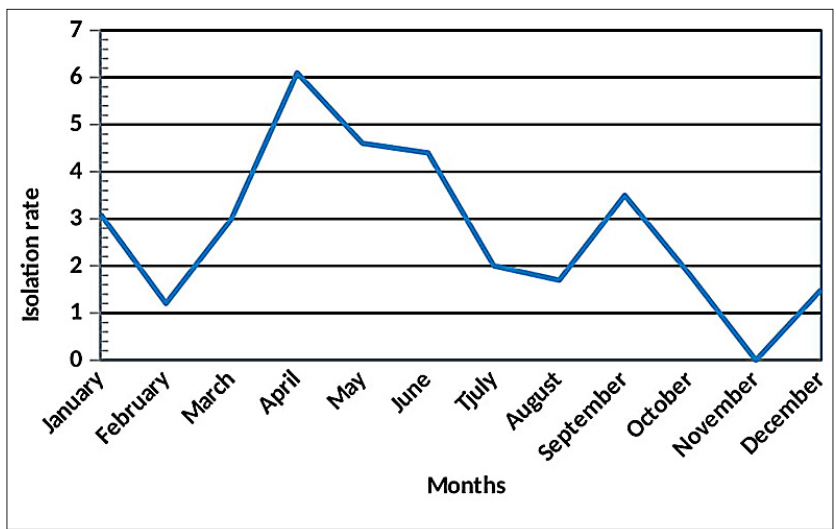

Figure 1. Comparison of $L$. pneumophila positive results by months

\section{DISCUSSION}

Legionnaires' disease is important for preventive medicine because it is a waterborne disease that leads to severe pneumonia which can result in death. Prevention of Legionella's settlement and proliferation in water-related areas and water systems constitutes the basic protection strategy for Legionnaires' disease [1]. While bacteria cause no health problems in most healthy individuals, they can cause very serious diseases in some individuals [11]. The Center for Disease Control (CDC) has reported that people over 50 years of age, smokers, people with chronic lung disease, and people with a weakened immune system, are at serious risk for Legionnaires' disease [12]. It is reported that the incidence of Legionnaires' disease in the USA has

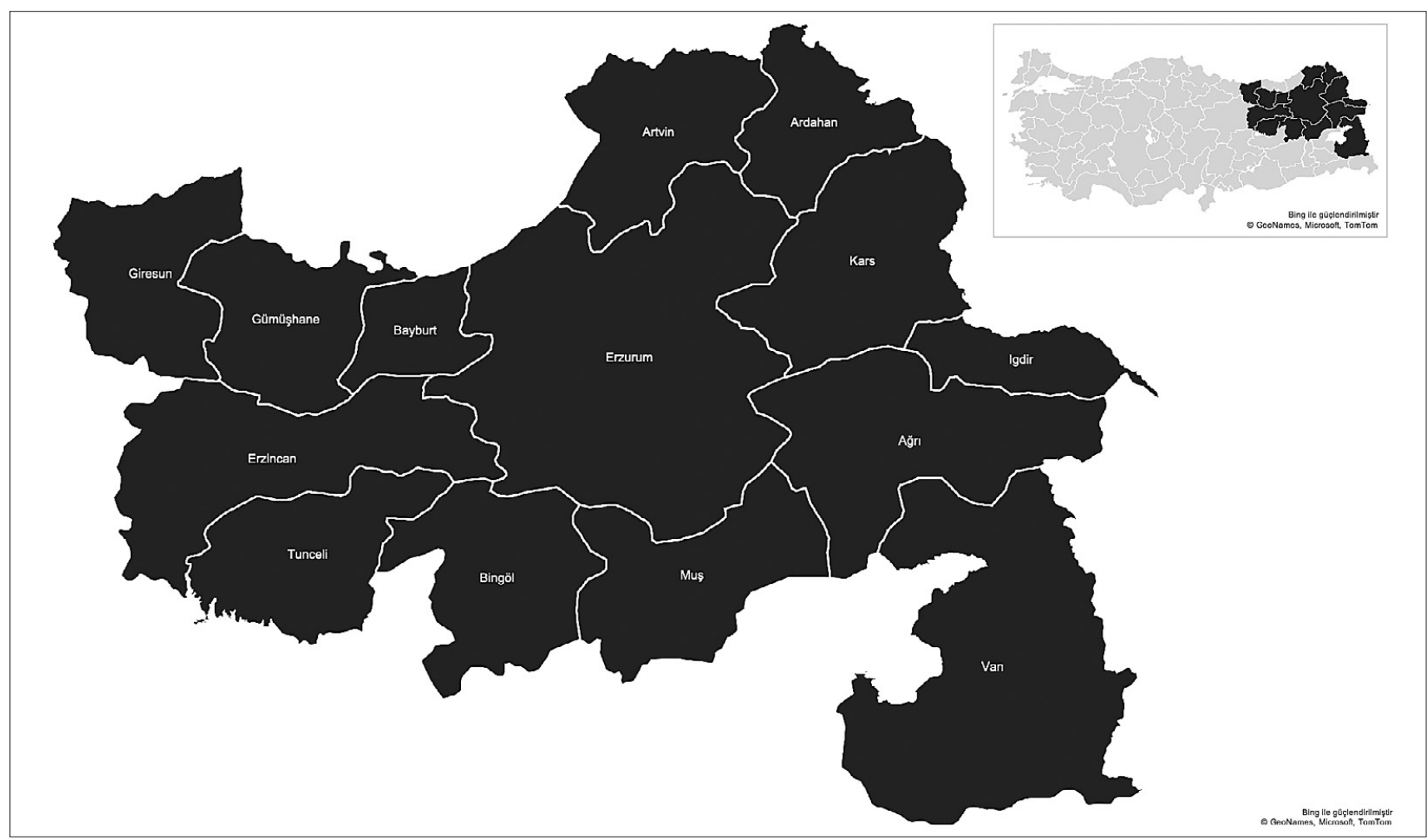

Figure 2. The provinces in eastern Turkey included in the study

provinces, the highest positivity rates were detected in the provinces of Tunceli (23.5\%), Gümüşhane (11.6\%), and Erzurum (4.4\%). No positivity was detected in any samples studied found in Ardahan, Bayburt, Giresun, Iğdır, and Van provinces (Fig. 3).

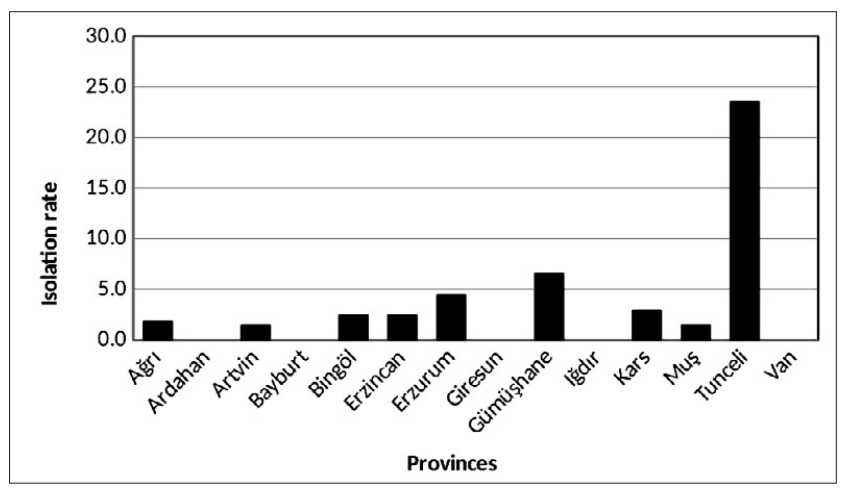

Figure 3. Distribution of $L$ pneumophila positive results by provinces increased four times since 2000, and the incidence in Europe has increased approximately three times since 1995 [13]. In $2016,7,069$ cases were reported in 30 European countries, of which $6,560(92.8 \%)$ were verified [14]. The disease is divided into three categories which are reported as follows: 1) approximately $70 \%$ of L. pneumophila cases are communityacquired, 2) $20 \%$ travel-related, and 3) $10 \%$ nosocomial [13].

Some studies show that $12 \%-70 \%$ of the water systems in hospitals involve Legionella bacteria colonization [15]. Stagnation of water at the usage points, in other words, at the end points, increases the colonization of Legionella. There are studies showing that stagnation in places such as sensor lavatory faucets, lavatory drainage pipes, ice machines, and decorative fountains are associated with nosocomial infection [16].

When evaluated at the national level, it is reported that the number of cases of Legionnaires' disease is the highest in countries such as Italy, France, Spain and Turkey [17]. In a 15year study by Lagana et al. [18] conducted in a hospital in Italy, 
$812(60 \%)$ of 1,346 water samples were Legionella positive. 588 (72\%) of the positive samples were L. pneumophila serogroup 2-14, and 147 (18\%) were L. pneumophila serogroup 1, and 119 (15\%) were non-L. pneumophila. Borella et al. [19] reported Legionella positivity in $60.5 \%$ of 119 samples taken from hot water systems in 40 hotels in Italy. Chochlakis et al. [20] reported Legionella colonization in 108 (6.9\%) samples in hot and cold water distribution systems in 1,495 water samples from 124 hotels in Greece. Yakunin et al. [21] demonstrated that $60 \%$ of the examined hotels were colonized with L. pneumophila, of which 470 (17\%) were Legionella-positive from 2,830 water specimens taken from 168 hotels in Israel.

Many hospital-related and hotel-related outbreaks of Legionnaires' disease were reported in Turkey. In a study by Erdoğan et al, [10] on an outbreak of Legionella that occurred in a newly-opened hotel in Alanya in 2009, Legionella was isolated from 11 out of 13 water samples taken, and all the positive samples were defined as L. pneumophila serogroup 1 in typing. Akkaya et al. [22] detected Legionella in 8 (6.7\%) of the 120 samples taken from schools, hospitals, hotels and houses in Kayseri, Turkey, in 2008. Özen et al. [23], in their study involving a total of 403 samples collected from 56 different hotels in Antalya, reported that L. pneumophila was isolated in $37.5 \%$ of the hotels and $10.1 \%$ of water samples. Ozen also reported that $85 \%$ of the samples were L. pneumophila serogroup 2-14 positive, and $15 \%$ of the samples were L. pneumophila serogroup 1 positive. Ignak et al. [24] detected Legionella colonization in 7\% of 100 samples taken from various departments of Istanbul Medical Faculty Hospital (three of which were L. pneumophila serogroup 1, and four were Legionella). In the presented study, L. pneumophila colonization was detected in 65 (3.2\%) of 2,025 samples, mostly taken from the water systems of hospitals. L. pneumophila positivity rate was found to be quite low. This is believed to be the result of the fact that the optimal reproductive temperature of legionella spp is $35^{\circ} \mathrm{C}$, and because the Erzurum province is the coldest region in Turkey the average temperature of mains water is quite low; therefore, the growth of Legionella is negatively affected. L. pneumophila serogroup 1 is reported as the species responsible for the majority of clinical cases in Europe and America [25]. In this study, the presence of serogroup 1 was found in $29.2 \%$ of positive samples while the most common was serogroup 2-14.

Due to reasons such as the characteristics of buildings, structure of the water system, organic content of the water, seasonal conditions and geographical factors, the isolation rate of Legionella bacteria varies from study to study [26]. In Israel, Sharaby et al. [27] reported in their study that the prevalence of Legionella in the water system and the resulting infection risk are seasonal, and twice as high in the summer months compared to the wintertime. In the current study, the highest number of cases was observed in April and May on an average of three years. No conclusion could be drawn regarding the reason for higher positivity in the spring.

Prevalence of L. pneumophila is reported to be higher in hot water systems that feed faucets and showers in health facilities, compared to the other species of Legionella [28, 29]. This opinion is also supported by the fact that in the current study, the three points with the highest positivity among the points from which samples were taken, were hot water faucets (11.6\%), hot water tanks (6.1\%) and shower heads $(4.8 \%)$, respectively.
This study was conducted using data from 14 provinces in eastern Turkey, and when comparison of the positivity rates of the samples taken from these provinces, the three provinces with the highest positivity rate were found to be Tunceli (23.5\%), Gümüşhane (11.6\%), and Erzurum (4.4\%). No Legionella bacteria were found in water samples taken from the provinces of Ardahan, Bayburt, Giresun, Iğdır and Van. Due to the retrospective nature of the study, no conclusions could be formed for the causes of this difference. The element iron is important for the reproduction and survival of Legionella because of it involvement as a co-factor in bacterial enzymes [10]. However, no information could be obtained about the iron content of the water samples taken from the provinces, the structure of the water systems or the age of the buildings. This was one of the limiting factors of the current study.

A Legionnaires' disease control programme has been carried out in Turkey since 1996 [11]. In considering the studies to determine the presence of Legionella in Turkey, the studies conducted in the western of our country are especially noteworthy. As no other study could be found for Legionella in Erzurum and nearby cities, the authors of the presented study believe it to be important for a number or reasons: it includes data obtained from the provinces in eastern Turkey with a cold climate, and it involves the biggest number of samples to date with respect to Legionella.

\section{CONCLUSIONS}

A summary of results of this study indicate that they differ from studies conducted by other researchers in different geographical regions of Turkey. The positivity rate of L. pneumophila is quite low compared to the other studies conducted the western part of the country. Since most of the water samples that involved growth of Legionella were taken from a hospital, the study emphasizes the importance of continuous observation, especially in water samples from hospitals to prevent the risk of hospital-induced legionellosis. The incidence rate of L. pneumopila serogroup 2-14 was higher than the incidence rate of serogroup 1. Legionella positivity was found to be higher in hot water systems of hospitals and related points, compared to the other sampling points. Furthermore, it is believed that the data obtained in this study can serve as important epidemiological data for Legionella surveillance control in Turkey. In addition, the results also indicate that further studies, such as molecular identification methods, are needed to identify the types of Legionella isolates and obtain more epidemiological data in Turkey.

\section{Acknowledgements}

The authors would like to thank to Dr. Gursel Bedir, Savas Calik, and the staff of the public health laboratory for their contributions to the study.

\section{REFERENCES}

1. Yavuz CI. As a Waterborne disease Legionnaire's disease and environmental survey. Türk Mikrobiyol Cem Derg. 2018; 48(4): 211-227. http:// dx.doi.org/10.5222/tmcd.2018.211

2. Vural T. Legionella Infections. ANKEM Derg. 2014; 28(2): 167-176.

3. Zhang Q, Zhou H, Chen R, et al. Legionnaires' disease caused by Legionella pneumophila serogroups 5 and 10, China. Emerg Infect Dis. 2014; 20(7): 1242. http://dx.doi.org/10.3201/eid2007.131343 
4. Control CfD, Prevention. Legionellosis---United States, 2000-2009. Morb Mort Weekly Rep. 2011; 60(32): 1083-1086.

5. Hines SA, Chappie DJ, Lordo RA, et al. Assessment of relative potentia for Legionella species or surrogates inhalation exposure from common water uses. Water Res. 2014; 56: 203-213. https://doi.org/10.1016/j. watres.2014.02.013

6. Lagana P, Moscato U, Poscia A, et al. Geostatistics-a tool applied to the distribution of Legionella pneumophila in a hospital water system. Ann. Agric. Environ Med. 2015; 22(4): 655-660. https://doi. org/10.5604/12321966.1185769

7. Cassier P, Landelle C, Reyrolle M, et al. Hospital washbasin water: risk of Legionella-contaminated aerosol inhalation. J Hosp Infect. 2013; 85(4): 308-311. https://doi.org/10.1016/j.jhin.2013.08.001

8. Ashbolt NJ. Environmental (Saprozoic) Pathogens of engineered water systems: understanding their ecology for risk assessment and management. Pathogens. 2015; 4(2): 390-405. https://doi.org/10.3390/ pathogens 4020390

9. Falkinham JO, Pruden A, Edwards M. Opportunistic premise plumbing pathogens: Increasingly important pathogens in drinking water. Pathogens. 2015; 4: 373-386. https://doi.org/10.3390/pathogens4020373

10. Erdoğan H, Arslan H. Evaluation of a Legionella outbreak emerged in a recently opening hotel. Mikrobiyol Bul. 2013; 47: 240-249. https:// doi.org/10.5578/mb.4353

11. Legionnaires disease control program guide. Ankara 2016: Ministry of Health, Public Health Agency of Turkey https://hsgm.saglik. gov.tr/depo/birimler/Bulasici-hastaliklar-db/hastaliklar/Lejyoner/ Lejyoner_Hastalik_Rehberi/Lejyoner_Hastaligi_Kontrol_Programi_ Rehberi_24072018.pdf (access: 2020.04.19).

12. Correia AM, Ferreira JS, Borges V, et al. Probable person-to-person transmission of Legionnaires' disease. N Engl J Med. 2016(5); 374: 497-8. http://dx.doi.org/10.1056/NEJMc1505356

13. Fitzhenry R, Weiss D, Cimini D, et al. Legionnaires' disease outbreaks and cooling towers, New York City, New York, USA. Emerg Infect Dis. 2017; 23(11): 1769. https://doi.org/10.3201/eid2311.161584

14. European Centre for Disease Prevention and Control. Legionnaires' disease. In: ECDC. Annual epidemiological report for 2016. Stockholm: ECDC; 2018. https://www.ecdc.europa.eu/sites/default/ files/documents/legionnaires-disease-annual-epidemiological-report. pdf (access: 2020.05.10).

15. Cunha BA, Burillo A, Bouza E. Legionnaires' disease. Lancet. 2016; 387(10016): 376-385. https://doi.org/10.1016/S0140-6736(15)60078-2

16. Decker BK, Palmore TN. Hospital water and opportunities for infection prevention. Curr Infect Dis Rep 2014; 16: 432. https://doi.org/10.1007/ s11908-014-0432-y

17. Joseph C, Ricketts K. Legionnaires' disease in Europe 2007-2008. Eurosurveillance 2010; 15(8): 19493.
18. Lagana P, Facciola A, Palermo R, et al. Environmental surveillance of Legionellosis within an Italian University Hospital-results of 15 years of analysis. Int J Environ Res Public Health. 2019; 16(7): 1103. https:// doi.org/10.3390/ijerph16071103

19. Borella P, Montagna MT, Stampi S, et al. Legionella contamination in hot water of Italian hotels. Appl Environ Microbiol. 2005; 71(10): 5805-5813. https://doi.org/10.1128/AEM.71.10.5805-5813.2005

20. Chochlakis D, Vassilios S, Christos P, et al. Typing of Legionella strains isolated from environmental samples in Crete, Greece, during the period 2004-2011. J Water Health. 2013; 11(4): 762-771. https://doi. org/10.2166/wh.2013.015

21. Yakunin E, Kostyal E, Agmon V, et al. A Snapshot of the Prevalence and Molecular Diversity of Legionella pneumophila in the Water Systems of Israeli Hotels. Pathogens. 2020; 9(6): 414. https://doi.org/10.3390/ pathogens 9060414

22. Akkaya Z, Ozbal YK. Legionella researging in water depots' of different buildings in Kayseri. J Health Sci. 2011; 20(1): 9-17.

23. Sepin-Ozen N, Tuglu-Ataman S, Emek M. Exploring the Legionella pneumophila positivity rate in hotel water samples from Antalya, Turkey. Environ Sci Pollut Res. Int 2017; 24(13): 12238-12242. https:// doi.org/10.1007/s11356-017-8864-1

24. Ignak S, Gurler B. An investigation of Legionella species in the water system of a university hospital. Türk Mikrobiyol Cem Derg. 2012; 42(3): 110-114. https://doi.org/doi:10.5222/TMCD.2012.110

25. Yu VL, Plouffe JF, Pastoris MC, et al. Distribution of Legionella species and serogroups isolated by culture in patients with sporadic communityacquired legionellosis: an international collaborative survey. J Infect Dis. 2002; 186(1): 127-128. https://doi.org/10.1086/341087

26. Costa J, Tiago I, da Costa MS, et al. Presence and persistence of Legionella spp. in groundwater. Appl Environ Microbiol. 2005; 271(2): 2663-671. http://dx.doi.org/10.1128/AEM.71.2.663-671.2005

27. Sharaby Y, Rodriguez-Martinez S, Hofle MG, et al. Quantitative microbial risk assessment of Legionella pneumophila in a drinking water supply system in Israel. Sci Total Environ. 2019; 671(2019): 404-410. https://doi.org/10.1016/j.scitotenv.2019.03.287

28. Boppe I, Bédard E, Taillandier C, et al. Investigative approach to improve hot water system hydraulics through temperature monitoring to reduce building environmental quality hazard associated to Legionella. Building and Environment. 2016; 108(2016): 230-239. https://doi.org/10.1016/j.buildenv.2016.08.038

29. Bargellini A, Marchesi I, Righi E, et al. Parameters predictive of Legionella contamination in hot water systems: association with trace elements and heterotrophic plate counts. Water Res. 2011; 45(6): 23152321. https://doi.org/10.1016/j.watres.2011.01.009 